\title{
Usefulness of and Factors Associated with Global Assessment Scale (GAS) Scores in Suicide Attempters
}

Miki Umetsu ${ }^{1}$, Kotaro Otsuka ${ }^{*}{ }^{1,2}$, Jin Endo ${ }^{1}$, Yasuhito Yoshioka ${ }^{1}$, Fumito Koizumi ${ }^{1}$, Ayumi Mizugai $^{1}$, Yoshifumi Onuma ${ }^{1,3}$, Toshinari Mita ${ }^{1}$, Kaoru Kudo ${ }^{1}$, Katsumi Sanjo ${ }^{1}$, Kentaro Fukumoto ${ }^{1}$, Hikaru Nakamura ${ }^{2}$, Akio Sakai ${ }^{1}$, Sigeatsu Endo ${ }^{3}$

${ }^{1}$ Department of Neuropsychiatry Iwate Medical University School of Medicine, Japan

${ }^{2}$ Department of Disaster and Community Psychiatry Iwate Medical University School of Medicine, Japan

${ }^{3}$ Department of Critical Care Medical Iwate Medical University School of Medicine, Japan

*Corresponding author: Kotaro Otsuka, Iwate Medical University School of Medicine, Japan, Tel: 81196264807; E-mail: kotaro29@df6.so-net.ne.jp

Received Date: October 16, 2014, Accepted Date: November 18, 2014, Published Date: November 25, 2014

Copyright: ( $) 2015$, Miki Umetsu et al., This is an open-access article distributed under the terms of the Creative Commons Attribution License, which permits unrestricted use, distribution, and reproduction in any medium, provided the original author and source are credited.

\begin{abstract}
Background: The purpose of this study is to determine, by classifying emergently admitted suicide attempter patients according to their Global Assessment Scale (GAS) scores, the characteristics of and factors associated with each group of patients.

Methods: The subjects of this study were 1,317 suicide attempters who were seen at the primary/secondary emergency department of the Iwate Medical University Hospital and at the Iwate Advanced Critical Care and Emergency Center, during the period of 7 years from April 1, 2006. These subjects were classified into three groups, consisting of the low, middle and high score groups, and were analyzed by comparing these groups with each other in terms of background factors and psychiatric assessment of emergency psychiatry case cards. Comparison examination was performed among 3 groups, and multiple logistic regression analysis was performed by using investigation items and the three GAS score groups as explanatory and dependent variables, respectively
\end{abstract}

Results: Factors associated with the low score group included being male, advanced age and unemployed, and high life event values. The odds of completed suicide in this group were more than 5 -fold higher than in the other two groups. Past history of suicide attempts was extracted as a factor associated with the middle score group. Factors associated with the high score group included: being female; young age; having no history of regular psychiatric visits; having history of advice seeking prior to the attempted suicide; and complex motives.

Conclusions: This paper determined characteristics of emergently admitted suicide attempters according to their GAS score levels, and proposed specific measures to be taken according to individual patients' GAS scores. It was suggested that in an emergency setting involving a suicide attempter, a global assessment of the patient and treatment given according to the assessment results may lead to the prevention of further suicide attempts.

Keywords Suicide attempt; Global assessment scale (GAS); Emergency psychiatry; Suicide prevention; Suicide

\section{Introduction}

Suicide occurs as a result of a multifactorial interaction between biological, genetic, psychosocial, environmental and other factors. It is therefore difficult to discuss risk of suicide on the basis of any single factor; instead, a comprehensive clinical assessment is necessary [1,2].

It has been pointed out that it is difficult to determine risk of suicide by a single scale. The Global Assessment Scale (GAS) is widely used in general clinical practice as well as research settings to assess overall psychosocial functional level. The GAS rates the general mental status (mental health level) at a certain time point along the continuum from psychological or psychiatric disorder to normal, and allows an assessment of the general mental status in terms of: achievement of social role activities; mental symptoms and reality testing; and possibility of suicide or violence. The GAS has been considered effective in developing treatment plans, assessing treatment response, and following up global improvement of patients, with the first report on this scale having already analyzed its reliability and validity using a variety of setups, producing good results [3-5].

Our previous studies on suicide attempts have revealed a tendency that, regardless of gender or age group, suicide attempters with lower GAS scores more often use dangerous methods of suicide in their attempts, indicating that GAS scores may be a predictor for dangerous suicide attempts not only across gender or age groups but also across disease entities [6,7]. However, there is not sufficient evidence that the GAS, a comprehensive indicator, is clearly related to the level of risk of suicide in patients. The purpose of this study is to clarify the characteristics and related factors associate with GAS of each group were classified into three groups in the GAS score a suicide attempters.

\section{Methods}

We hypothesized that the lead to the prevention of re-suicide attempt by taking action appropriate to the score to understand the characteristics according GAS score's suicide attempt. This retrospective cohort design was from April 1, 2006 to March 31, 2013.The population was 208,930 patients $(11,895$ of who were psychiatric emergency patients) who were seen at the primary/ 
secondary emergency department of the Iwate Medical University Hospital (the "Hospital") and at the Iwate Advanced Critical Care and Emergency Center (the "Center") attached to the Hospital, during the period of the study. In the emergency system of the target area of this study, because nearly all cases of emergency patients related to mental illness is transported to this institution, we have selected this institution Of these, 1,317 patients who met the criteria for the diagnosis of suicide attempt (i.e., (i) the patient confirms that he/she attempted suicide, (ii) the patient left a suicide note or gave advance notice of suicide, (iii) there is a witness/es of suicidal acts, or (iv) it was concluded by judicial personnel or by autopsy that the patient attempted suicide [8] were included in this study. Suicide completers were defined as those who were pronounced dead upon arrival at the Center or who died within 24 hours of admission. We have excluded 29 patients GAS were unknown among subjects when compared between the three groups. In addition, it was discussed to clarify the characteristics for excluded 29 people (Figure1).

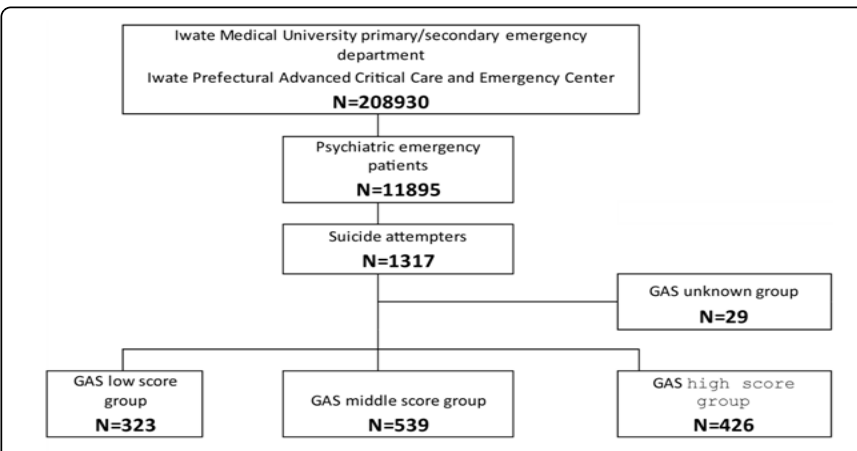

Figure 1: Flowchart of Subjects

Each subject was assessed based on information obtained from the patient and his/her entourage (such as family members, emergency squad, and hospital staff and primary care physician) in the course of psychiatric emergency. Suicide completers were assessed in the same manner as above if the patient had been seen at our department immediately before his/her emergency admission or if a medical interview was possible at the time of consultation. Assessment and diagnosis were performed by one of the two emergency psychiatrists or the Hospital's eleven psychiatrists on duty, under the supervision of one senior psychiatrist (who is a designated psychiatrist). All psychiatrists who participated in this study had a training period in advance, during which they underwent an assessment training program under the guidance of a senior attending physician. The commencement of the data collection is suicide attempt patients visited the emergency department; completion is a time when suicide attempt patients were discharged from the hospital or when he/she died.

According to their GAS scores, the subjects were classified into: the low score group who scored 20 points or lower; the middle score group who scored between 21 and 40 points; and the high score group who scored 41 points or higher. As clinical assessment criteria for GAS score categories, anchor points have been set between 10-point score categories. The low, middle and high score groups correspond respectively to: the level associated with imminent risk of suicide attempts and requiring monitoring; the level associated with no obvious risk of suicide but requiring psychiatric inpatient treatment; and levels varying from good social health to the level requiring psychiatric outpatient care. An analysis was performed by comparing the three groups with each other in terms of the investigation items, which included, out of the items listed on the Hospital's information sheet on accepted emergency outpatient: such background factors as gender, age, years of education, presence/absence of persons living with the patient, and employment status; diagnosis according to the "Mental and Behavioral Disorders" listed in the 10th Revision of the International Classification of Diseases [9] ("ICD-10"); whether a new or return visit patient at the Hospital; history of psychiatric consultation at the time of consultation; history of continuous regular psychiatric visits; history of advice seeking prior to the attempted suicide; history of suicide attempts (in the past and within the previous year); motives(Family/family member, Interpersonal relationship et al); methods of suicide attempt; life change units (LCU) of the Holmes Social Readjustment Rating Scale [10] total score of the Japanese version of the Oxford University version of the Brief Psychiatric Rating Scale (BPRS) [11]; physical severity; treatment given(Physical treatment, Psychiatric therapy et al); and outcome at the emergency outpatient department(Psychiatric hospitalization, Emergency hospitalization, Discharge to home). Diagnosis according to the ICD-10 was made based on information from those around the patients, past psychiatric history and outpatient diagnosis, including interviews conducted during the period from consultation to discharge. In terms of physical severity, the subjects were classified into the absolutely dangerous (AD) group and the relatively dangerous (RD) group, according to the criteria proposed by Asukai [12]. In previous research, LCU and BPRS is analyzed the reliability among evaluators, producing good results $[11,13]$.

In three-group comparisons, ratios were tested by chi-square test and mean values by one-way analysis of variance. Two-group comparisons were tested by the Bonferroni method. In addition, multiple logistic regression analysis was performed with the intention of determining factors associated with GAS score classification, by grouping all investigation items into pre-attempt items (gender, age, years of education, presence/absence of persons living with the patient, employment status, ICD-10 diagnosis, history of psychiatric consultation, history of regular psychiatric visits, history of advice seeking prior to the attempted suicide, past history of suicide attempts, history of suicide attempts within the previous year, total LCU score, and motives) and post-attempt items (new patient, total BPRS score, methods of suicide attempt, physical severity ( $\mathrm{AD} / \mathrm{RD}$ group), treatment given, and outcome), and by using the items within these groups as explanatory variables and using the GAS low, middle and high score groups as dependent variables. All tests used a significance level of 5\%, with significance probabilities expressed in numbers. SPSS $21.0 \mathrm{~J}$ for Windows was used in all statistical procedures. Personally identifiable information was excluded from data. Consideration was given to the protection of personal information in the process of data management and processing. This study has been approved by the Ethics Committee of the Iwate Medical University, Faculty of Medicine.

\section{Results}

Of all 1,317 patients, $382(29 \%)$ and $935(71 \%)$ were men and women, respectively. In terms of GAS scores, 323 (24.5\%), 539 (40.9\%) and $426(32.3 \%)$ patients were classified into the low, middle and high score groups, respectively, with the respective mean values of 14.79 , 35.22 and 54.99. There were 57 suicide completers, including 33 patients who were pronounced dead upon admission at the Center and 
Citation: Umetsu M, Otsuka K, Endo J, Yoshioka Y, Koizumi F, et al. (2015) Usefulness of and Factors Associated with Global Assessment

24 patients who died within 24 hours of admission. There were 29 patients whose GAS scores were unknown, 24 of who were suicide completers.

\begin{tabular}{|c|c|c|c|c|c|c|c|c|}
\hline \multirow{3}{*}{ Item } & \multirow{3}{*}{\begin{tabular}{|l} 
Low score group \\
$n=323$ \\
Ave(SD) \\
\end{tabular}} & \multirow{3}{*}{$\begin{array}{l}\begin{array}{l}\text { Middle score } \\
\text { group }\end{array} \\
\mathrm{n}=539 \\
\text { Ave(SD) }\end{array}$} & \multirow{3}{*}{$\begin{array}{l}\text { High score group } \\
n=426 \\
\text { Ave(SD) }\end{array}$} & \multirow{3}{*}{$p$-value } & \multicolumn{3}{|c|}{ Bonferroni method } & \multirow{2}{*}{$\begin{array}{l}\begin{array}{l}\text { Patients with } \\
\text { unknown } \\
\text { scores }\end{array} \\
n=29\end{array}$} \\
\hline & & & & & \multirow{2}{*}{ Low-mid. } & & & \\
\hline & & & & & & Mid-high & Low-high & \\
\hline Mean age ${ }^{\star \star}$ & $41.91(18.478)$ & $35.85(15.618)$ & $34.00(15.440)$ & $<0.001$ & $<0.001$ & n.s & $<0.001$ & 48.03(16.571) \\
\hline Years of education** & $11.66(2.316)$ & $11.79(2.214)$ & $11.71(2.255)$ & n.s. & & & & \\
\hline Total LCU score ${ }^{* *}$ & $35.92(42.017)$ & $27.67(37.639)$ & $24.76(28.877)$ & $<0.001$ & 0.004 & n.s. & $<0.001$ & $11.48(24.571)$ \\
\hline Total BPRS score ${ }^{\star *}$ & $16.77(12.449)$ & 19.65(13.397) & $14.64(9.837)$ & $<0.001$ & 0.004 & $<0.001$ & $<0.001$ & \\
\hline Item & $N(\%)$ & $\mathrm{N}(\%)$ & $\mathrm{N}(\%)$ & & \multicolumn{3}{|c|}{ Residual analysis } & \\
\hline Male* $^{*}$ & $134(41.5)$ & $136(25.2)$ & $93(21.8)$ & $<0.001$ & $6.1<-2.0<-$ & & & 19(65.5) \\
\hline Living alone* & $54(16.7)$ & $86(16.9)$ & $68(16.9)$ & n.s. & & & & $4(13.8)$ \\
\hline Unemployed* & $226(70.0)$ & $352(65.3)$ & $226(53.1)$ & $<0.001$ & $3.2<1.8<-4$ & & & 11(37.9) \\
\hline \multicolumn{9}{|l|}{ ICD diagnosis* } \\
\hline F0 & $10(3.1)$ & $10(1.9)$ & $7(1.6)$ & n.s. & & & & $2(6.9)$ \\
\hline $\mathrm{F} 1$ & $5(1.5)$ & $16(3.0)$ & $9(2.1)$ & n.s. & & & & $0(0)$ \\
\hline $\mathrm{F} 2$ & $48(14.9)$ & $71(13.2)$ & $36(8.5)$ & 0.016 & \multicolumn{3}{|c|}{$1.8<1.1<-2.8$} & $3(10.3)$ \\
\hline F3 & $168(52.0)$ & $225(41.7)$ & $157(36.9)$ & $<0.001$ & \multicolumn{3}{|c|}{$3.9<-0.6<-3.0$} & $8(27.6)$ \\
\hline F4 & $53(16.4)$ & $142(26.3)$ & $152(35.7)$ & $<0.001$ & \multicolumn{3}{|c|}{$-4.9<-0.4<5.0$} & $3(10.3)$ \\
\hline F6 & $20(6.2)$ & $45(8.3)$ & $41(9.6)$ & n.s. & & & & $0(0)$ \\
\hline Other & $19(5.9)$ & $29(5.4)$ & $22(5.2)$ & n.s. & & & & $2(6.9)$ \\
\hline Unknown & $0(0)$ & $1(0.2)$ & $2(0.5)$ & n.s. & & & & 11(37.9) \\
\hline New patient at Hospital ${ }^{\star}$ & $187(57.9)$ & $242(44.9)$ & $207(48.6)$ & 0.001 & \multicolumn{3}{|c|}{$3.5<-2.7<-0.4$} & $24(82.8)$ \\
\hline $\begin{array}{l}\text { No history of psychiatric } \\
\text { consultation* }\end{array}$ & $126(41.4)$ & $166(32.4)$ & $169(36.7)$ & 0.011 & \multicolumn{3}{|c|}{$1.7<-3.0<1.5$} & 11(37.9) \\
\hline $\begin{array}{l}\text { Current regular psychiatric } \\
\text { outpatient* }^{*}\end{array}$ & $132(40.9)$ & $245(45.5)$ & $143(33.6)$ & 0.001 & \multicolumn{3}{|c|}{$2.0<3.2<-3.5$} & $4(13.8)$ \\
\hline Pre-attempt advice seeking ${ }^{*}$ & $50(15.5)$ & $77(14.3)$ & $82(19.2)$ & n.s. & & & & $0(0)$ \\
\hline History of suicide attempts* & $150(46.4)$ & $302(56.0)$ & $230(54.0)$ & 0.021 & \multicolumn{3}{|c|}{$-2.7<1.9<0.5$} & $5(17.2)$ \\
\hline $\begin{array}{l}\text { History of suicide attempts } \\
\text { within the previous year* }\end{array}$ & $106(32.8)$ & $207(38.4)$ & $167(39.2)$ & n.s. & & & & $2(6.9)$ \\
\hline \multicolumn{9}{|l|}{ Motive* $^{*}$} \\
\hline Family/family member & $80(24.8)$ & $134(24.9)$ & $88(20.7)$ & n.s. & & & & $1(3.4)$ \\
\hline Financial condition & $21(6.5)$ & $26(4.8)$ & $15(3.5)$ & n.s. & & & & $1(3.4)$ \\
\hline Illness & $31(9.6)$ & $39(7.2)$ & $26(6.1)$ & n.s. & & & & $3(10.3)$ \\
\hline Psychosis & $34(10.5)$ & $57(10.6)$ & $36(8.5)$ & n.s. & & & & $2(6.9)$ \\
\hline Interpersonal relationship & $43(13.3)$ & $99(18.4)$ & $93(21.8)$ & 0.011 & $-2.7<0.1<2$ & & & $1(3.4)$ \\
\hline
\end{tabular}


Citation: Umetsu M, Otsuka K, Endo J, Yoshioka Y, Koizumi F, et al. (2015) Usefulness of and Factors Associated with Global Assessment

\begin{tabular}{|c|c|c|c|c|c|c|}
\hline Work & $26(8.0)$ & $45(8.3)$ & $31(7.3)$ & n.s. & & $1(3.4)$ \\
\hline Combination & $41(12.7)$ & $73(13.5)$ & $74(17.4)$ & n.s. & & $1(0)$ \\
\hline Other & $12(3.7)$ & $23(4.3)$ & $29(6.8)$ & n.s. & & $1(3.4)$ \\
\hline Unknown & $35(10.8)$ & $43(8.0)$ & $34(8.0)$ & n.s. & & $18(62.1)$ \\
\hline \multicolumn{7}{|l|}{ Method* } \\
\hline Drug overdose & 124(38.4) & $312(57.9)$ & 251(58.9) & $<0.001$ & $-6.2<2.8<2.8$ & $2(6.9)$ \\
\hline Use of knife & $53(16.4)$ & $85(15.6)$ & $67(15.7)$ & n.s. & & $1(3.4)$ \\
\hline Poisoning & $28(8.7)$ & $27(5.0)$ & $19(4.5)$ & n.s. & & $2(6.9)$ \\
\hline Hanging & $27(8.4)$ & $22(4.1)$ & $15(3.5)$ & 0.005 & $3.2<-1.2<-1.7$ & $6(20.7)$ \\
\hline Jumping from height & $26(8.0)$ & $18(3.3)$ & $12(2.8)$ & 0.001 & $3.8<-1.5<-1.9$ & $8(27.6)$ \\
\hline Vehicular impact & $2(0.6)$ & $2(0.4)$ & $1(0.2)$ & n.s. & & $0(0)$ \\
\hline Use of gas & $24(7.4)$ & $20(3.7)$ & $10(2.3)$ & 0.002 & $3.4<-0.7<-2.3$ & $3(10.3)$ \\
\hline Drowning & $3(0.9)$ & $5(0.9)$ & $8(1.9)$ & n.s. & & $2(6.9)$ \\
\hline Self-burning & $9(2.8)$ & $8(1.5)$ & $2(0.5)$ & n.s. & & $4(13.8)$ \\
\hline Combination & $24(7.4)$ & $35(6.5)$ & $37(8.7)$ & n.s. & & $0(0)$ \\
\hline Other & $3(0.9)$ & $5(0.9)$ & $4(0.9)$ & n.s. & & $2(6.9)$ \\
\hline AD group* & $100(31.0)$ & 107(19.9) & $61(14.3)$ & $<0.001$ & $5.2<-0.7<-4.0$ & $27(93.1)$ \\
\hline \multicolumn{7}{|l|}{ Treatment ${ }^{*}$} \\
\hline Psychotropic infusion & $15(4.6)$ & $26(4.8)$ & $50(11.7)$ & $<0.001$ & $-2.0<-2.7<4.6$ & 0 \\
\hline Psychotropic prescription & $6(1.6)$ & $20(3.7)$ & $11(2.6)$ & n.s. & & 0 \\
\hline Psychiatric therapy & $120(37.2)$ & 184(34.1) & $137(32.2)$ & n.s. & & 0 \\
\hline Physical treatment & $273(84.5)$ & $471(87.4)$ & $348(81.7)$ & n.s. & & $29(100)$ \\
\hline \multicolumn{7}{|l|}{ Outcome* } \\
\hline Discharge to home & $42(13.0)$ & $117(21.7)$ & $148(34.7)$ & $<0.001$ & $-5.3<-1.5<6.5$ & $0(0)$ \\
\hline Psychiatric hospitalization & $165(51.1)$ & $273(50.6)$ & $173(40.6)$ & 0.003 & $1.5<2.0<-3.4$ & $0(0)$ \\
\hline Emergency hospitalization & $90(27.9)$ & $136(25.2)$ & $91(21.4)$ & n.s. & & $10(34.5)$ \\
\hline Completed suicide* & $22(6.8)$ & $4(0.7)$ & $6(1.4)$ & $<0.001$ & $5.8<-3.4<-1.7$ & $25(86.2)$ \\
\hline
\end{tabular}

Table1: Three-group Comparison, ${ }^{\star}$ Chi-square test ${ }^{* *}$ One-way analysis of variance Background factors

In terms of gender, the proportion of men tended to be higher in lower GAS score groups, with men accounting for $41.5 \%, 25.2 \%$ and $21.8 \%$ of the low, middle and high GAS score groups, respectively. The mean age was higher in lower score groups, with the mean age of $41.91,35.85$ and 34.0 years in the low, middle and high score groups, respectively.

The proportion of unemployed was higher in the low score group and lower in the high score group, and middle and high score groups, respectively.
ICD-10 diagnosis, history of psychiatric consultation, advice seeking, history of suicide attempts, life events and motives

As for ICD-10 diagnosis at consultation, a significant difference was observed in F2 (schizophrenia), F3 (mood disorders) and F4 (neurosis). F2 and F3 were found less often in the high score group, with $8.5 \%$ and $36.9 \%$ of the high score group diagnosed with F2 $(\mathrm{p}=0.016)$ and $\mathrm{F} 3$, respectively, as compared to the higher percentage $(52.0 \%)$ of patients diagnosed with F3 in the low score group $(\mathrm{p}<$ $0.001)$. Conversely, F4 was found more often in the high score group $(35.7 \%)$ and less often in the low score group (16.4\%). The proportion of new patients at the Hospital was higher at $57.9 \%$ in the low score group and lower at $44.9 \%$ in the middle score group. The proportion of patients with no history of psychiatric consultation at the time of 
consultation was significantly lower at $32.4 \%$ in the middle score group. The proportion of current regular psychiatric outpatients was higher in the low and middle score groups, at $40.9 \%$ and $45.5 \%$, respectively, and was lower at $33.6 \%$ in the high score group. As for history of advice seeking prior to the suicide attempt, no significant difference was observed between the three groups. The proportion of patients with past history of suicide attempts was lower at $46.4 \%$ in the low score group, whereas no significant difference was observed between the three groups in terms of history of suicide attempts within the previous year.

The mean total LCU score was higher in the low score group, with the mean score of 35.92, 27.67 and 24.76 in the low, middle and high score groups. As for motives, only in interpersonal relationship a difference was observed between the three groups. The proportion of patients whose motive for the suicide attempt was interpersonal relationship was low in the lower score group and higher in the high score group, at $13.3 \%, 18.4 \%$ and $21.8 \%$ in the low, middle and high score groups, respectively .

\section{BPRS scores}

The mean total BPRS score was higher in the middle group, with the mean score of 16.8, 19.7 and 14.6 in the low, middle and high score groups, respectively. The psychiatric symptoms observed significantly more frequently in the middle score group were anxiety, emotional withdrawal, uncooperativeness and affective flattening.

\section{Means of suicide attempt, physical severity, outcome and treatment}

Regarding methods of suicide attempt, a difference was seen in drug overdose, hanging, jumping from height and use of gas between the three groups. Drug overdose was used more often in higher GAS score groups, with $38.4 \%, 57.9 \%$ and $58.9 \%$ of patients in the low, middle and high score groups using this method. Hanging, jumping from height, and use of gas were more often seen in the low score group, at $8.4 \%, 8.0 \%$ and $7.4 \%$, respectively. The proportion of patients classified into the $\mathrm{AD}$ group, which is associated with severe physical consequences, was also higher in the low score group and lower in the high score group, at $31.0 \%, 19.9 \%$ and $14.3 \%$ in the low, middle and high score groups, respectively.

As for treatment given on the day, a difference was observed in psychotropic drug treatment at the emergency department, which tended to be given more often to higher GAS score groups, with $4.6 \%$, $4.8 \%$ and $11.7 \%$ of patients in the low, middle and high score groups receiving this treatment, respectively. In terms of outcome, the proportion of patients who were discharged to home was lower in the low score group and higher in the high score group, at 13.0\%, $21.7 \%$ and $34.7 \%$ in the low, middle and high score groups, respectively. Psychiatric hospitalization was seen more often in low and middle score groups and less often in the high score group, at 51.1\%, 50.6\% and $40.6 \%$ in the low, middle and high score groups, respectively. However, no significant difference was observed in hospitalization to any ward at the Center between the three groups. The proportion of suicide completers was higher in the low score group and lower in the middle score group, at $6.8 \%, 0.7 \%$ and $1.4 \%$ in the low, middle and high score groups, respectively.

\section{Patients whose GAS scores are unknown}

In patients whose GAS scores are unknown, there were high proportions of: men; patients with advanced age; and those who were classified into the AD group as having used hanging, jumping from height, gas, self-burning, etc. as methods of suicide. Eighty-six percent of these patients were suicide completers.

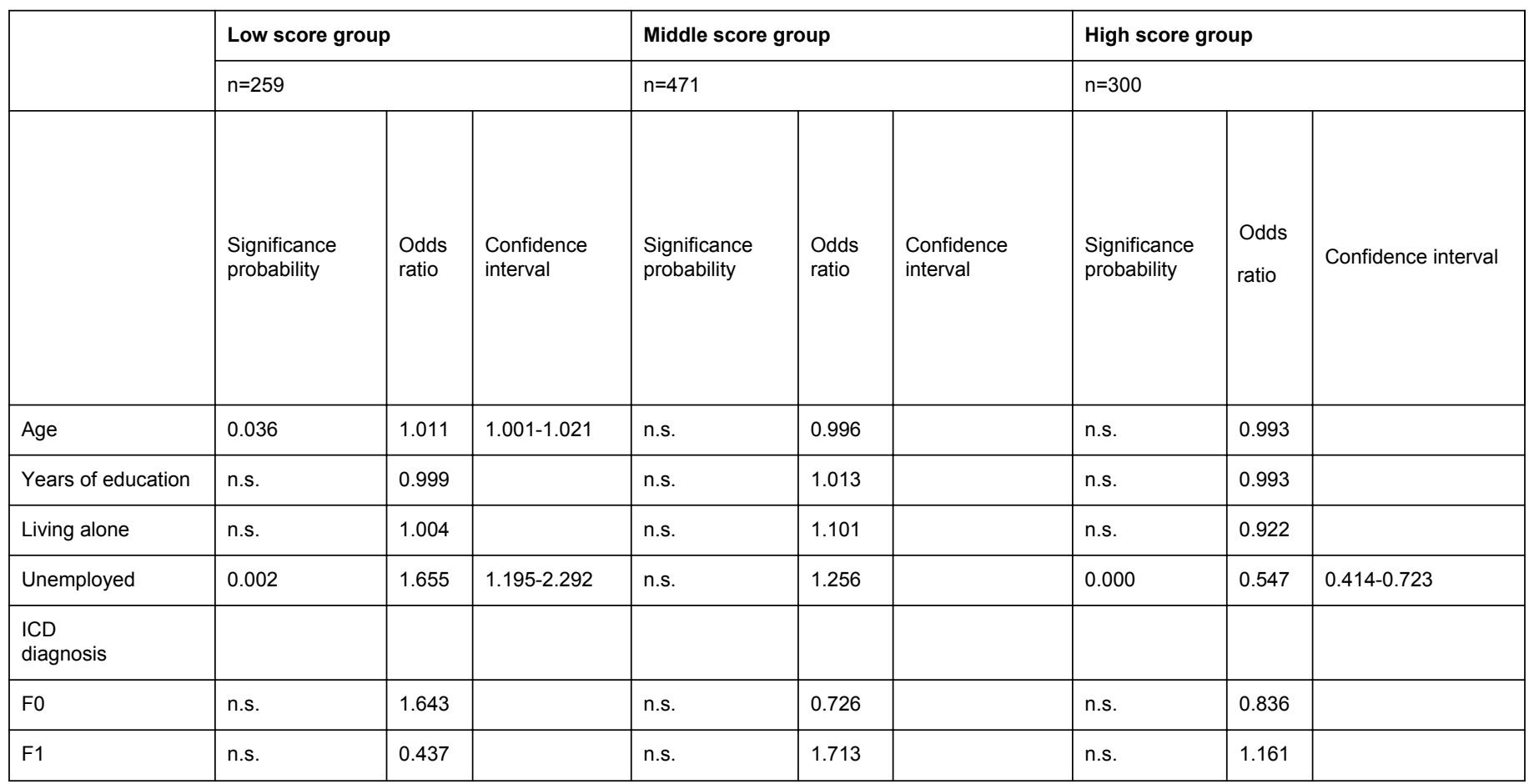


Citation: Umetsu M, Otsuka K, Endo J, Yoshioka Y, Koizumi F, et al. (2015) Usefulness of and Factors Associated with Global Assessment

\begin{tabular}{|c|c|c|c|c|c|c|c|c|c|}
\hline F2 & n.s. & 1.598 & & n.s. & 1.063 & & n.s. & 0.623 & \\
\hline F3 & n.s. & 1.482 & & n.s. & 1.007 & & n.s. & 0.773 & \\
\hline F4 & n.s. & 0.909 & & n.s. & 0.860 & & n.s. & 1.266 & \\
\hline F6 & n.s. & 1.038 & & n.s. & 0.750 & & n.s. & 1.372 & \\
\hline $\begin{array}{l}\text { No history of } \\
\text { psychiatric } \\
\text { consultation }\end{array}$ & n.s. & 1.435 & & n.s. & 0.849 & & n.s. & 0.959 & \\
\hline $\begin{array}{l}\text { Current regular } \\
\text { psychiatric } \\
\text { outpatient }\end{array}$ & n.s. & 1.472 & & n.s. & 1.210 & & 0.005 & 0.619 & \\
\hline $\begin{array}{l}\text { Pre-attempt advice } \\
\text { seeking }\end{array}$ & n.s. & 0.849 & & n.s. & 0.718 & & 0.002 & 1.758 & \\
\hline $\begin{array}{l}\text { History of suicide } \\
\text { attempts }\end{array}$ & n.s. & 0.790 & & 0.036 & 1.480 & $1.026-2.135$ & n.s. & 0.781 & \\
\hline $\begin{array}{l}\text { History of suicide } \\
\text { attempts within the } \\
\text { previous year }\end{array}$ & n.s. & 1.424 & & 0.026 & 0.659 & $0.456-0.952$ & n.s. & 1.272 & \\
\hline Total LCU score & 0.002 & 1.006 & $1.002-1.011$ & n.s. & 1.001 & & 0.000 & 0.992 & $0.987-0.996$ \\
\hline \multicolumn{10}{|l|}{ Motive } \\
\hline $\begin{array}{l}\text { Family/family } \\
\text { members }\end{array}$ & n.s. & 0.611 & & n.s. & 1.470 & & n.s. & 1.281 & \\
\hline Financial condition & n.s. & 0.744 & & n.s. & 1.112 & & n.s. & 1.286 & \\
\hline Illness & n.s. & 0.524 & & n.s. & 1.543 & & n.s. & 1.219 & \\
\hline Psychosis & n.s. & 0.611 & & n.s. & 1.498 & & n.s. & 1.193 & \\
\hline $\begin{array}{l}\text { Interpersonal } \\
\text { relationship }\end{array}$ & 0.003 & 0.391 & $0.209-0.703$ & n.s. & 1.586 & & n.s. & 1.544 & \\
\hline Work & n.s. & 0.662 & & n.s. & 1.563 & & 0.835 & 1.075 & \\
\hline Complex & 0.007 & 0.410 & $0.215-0.783$ & n.s. & 1.179 & & 0.009 & 2.270 & $1.228-4.196$ \\
\hline Other & 0.015 & 0.348 & $0.148-0.816$ & n.s. & 1.059 & & 0.008 & 2.665 & $1.291-5.502$ \\
\hline
\end{tabular}

Valid number of subjects: 1146

Missing cases: 171

Table 2: Multiple Logistic Regression Analysis (Pre-attempt)

\begin{tabular}{|c|c|c|c|c|c|c|c|c|c|}
\hline & \multicolumn{3}{|c|}{ Low score group } & \multicolumn{3}{|c|}{ Middle score group } & \multicolumn{3}{|l|}{ High score group } \\
\hline & \multicolumn{3}{|l|}{$n=287$} & \multicolumn{3}{|l|}{$n=518$} & \multicolumn{3}{|l|}{$n=396$} \\
\hline & $\begin{array}{l}\text { Significance } \\
\text { probability }\end{array}$ & Odds ratio & $\begin{array}{l}\text { Confidence } \\
\text { interval }\end{array}$ & $\begin{array}{l}\text { Significanc } \\
\text { e } \\
\text { probability }\end{array}$ & Odds ratio & $\begin{array}{l}\text { Confidence } \\
\text { interval }\end{array}$ & Significance probability & $\begin{array}{l}\text { Odds } \\
\text { ratio }\end{array}$ & $\begin{array}{l}\text { Confidence } \\
\text { interval }\end{array}$ \\
\hline New patient & n.s. & 1.242 & & .021 & .746 & $0.582-0.957$ & n.s. & 1.143 & \\
\hline Total BPRS score & n.s. & .991 & & .000 & 1.035 & $1.024-1.046$ & .000 & .965 & $0.953-0.978$ \\
\hline \multicolumn{10}{|l|}{ Method } \\
\hline Drug overdose & n.s. & 1.319 & & n.s. & 1.167 & & n.s. & 1.032 & \\
\hline Use of knife & n.s. & 2.412 & & n.s. & .890 & & n.s. & .865 & \\
\hline Poisoning & n.s. & 4.046 & & n.s. & .766 & & n.s. & .600 & \\
\hline
\end{tabular}


Citation: Umetsu M, Otsuka K, Endo J, Yoshioka Y, Koizumi F, et al. (2015) Usefulness of and Factors Associated with Global Assessment

Page 7 of 10

\begin{tabular}{|c|c|c|c|c|c|c|c|c|c|}
\hline Hanging & n.s. & 2.686 & & n.s. & .823 & & n.s. & .862 & \\
\hline $\begin{array}{ll}\text { Jumping } & \text { from } \\
\text { height } & \end{array}$ & n.s. & 5.127 & & n.s. & .535 & & n.s. & .627 & \\
\hline Vehicular impact & n.s. & 5.294 & & n.s. & .343 & & n.s. & .951 & \\
\hline Use of gas & n.s. & 3.625 & & n.s. & .695 & & n.s. & .662 & \\
\hline Drowning & n.s. & 1.359 & & n.s. & .305 & & n.s. & 3.772 & \\
\hline Self-burning & n.s. & 3.942 & & n.s. & 1.605 & & n.s. & .000 & \\
\hline Combination & n.s. & 1.987 & & n.s. & .810 & & n.s. & 1.128 & \\
\hline$A D$ group & n.s. & 1.036 & & n.s. & 1.197 & & n.s. & .743 & \\
\hline \multicolumn{10}{|l|}{ Treatment } \\
\hline $\begin{array}{l}\text { Psychotropic } \\
\text { treatment }\end{array}$ & n.s. & .769 & & .010 & .481 & $0.276-0.837$ & .001 & 2.463 & $1.449-4.418$ \\
\hline $\begin{array}{l}\text { Psychotropic } \\
\text { prescription }\end{array}$ & n.s. & .542 & & .002 & 3.452 & $1.560-7.641$ & .045 & .417 & $0.117-0.982$ \\
\hline Psychiatric therapy & n.s. & 1.367 & & n.s. & 1.269 & & .000 & .584 & $0.436-0.782$ \\
\hline Physical treatment & n.s. & .713 & & .013 & 1.671 & $1.112-2.509$ & n.s. & .776 & \\
\hline \multicolumn{10}{|l|}{ Outcome } \\
\hline $\begin{array}{l}\text { Discharged to } \\
\text { home }\end{array}$ & n.s. & .467 & & n.s. & 1.004 & & n.s. & 1.895 & \\
\hline $\begin{array}{l}\text { Emergency } \\
\text { hospitalization }\end{array}$ & n.s. & .755 & & n.s. & 1.384 & & n.s. & 1.056 & \\
\hline $\begin{array}{l}\text { Psychiatric } \\
\text { hospitalization }\end{array}$ & n.s. & 1.066 & & n.s. & 1.208 & & n.s. & .875 & \\
\hline Completed suicide & .018 & 5.257 & $1.328-20.811$ & n.s. & .000 & & n.s. & 1.253 & \\
\hline
\end{tabular}

Valid number of subjects: 1202

Missing cases: 115

Table 3: Multiple Logistic Regression Analysis (Contemporaneous \& Post-attempt)

Significant pre-attempt influencing factors for the occurrence of the low score group were being male $(\mathrm{OR}=1.851)$, age $(\mathrm{OR}=1.011)$, being unemployed $(\mathrm{OR}=1.655)$, and total $\mathrm{LCU}$ score $(\mathrm{OR}=1.006)$. In terms of motives, interpersonal relationship $(\mathrm{OR}=0.391)$, complex motives $(\mathrm{OR}=0.410)$, and other motives $(\mathrm{OR}=0.348)$ were extracted. The significant contemporaneous and post-attempt influencing factor for the occurrence of the low score group was completed suicide $(\mathrm{OR}=5.257)$. Extracted as significant pre-attempt influencing factors for the occurrence of the middle score group were past history of suicide attempts $(\mathrm{OR}=1.480)$ and history of suicide attempts within the previous year $(\mathrm{OR}=0.659)$.Extracted as significant contemporaneous and post-attempt influencing factors for the middle score group were: being new patients at the Hospital $(\mathrm{OR}=0.746)$; and psychotropic drug treatment $(\mathrm{OR}=0.481)$ or prescription $(\mathrm{OR}=3.452)$ and physical procedure $(\mathrm{OR}=1.671)$ as treatment given. Significant pre-attempt influencing factors for the occurrence of the high score group were: being male $(\mathrm{OR}=0.686)$; being unemployed $(\mathrm{OR}=0.547)$; current regular psychiatric outpatients $(\mathrm{OR}=0.619)$; pre-attempt advice seeking ( $\mathrm{OR}=1.758)$; and $\mathrm{LCU}$ score $(\mathrm{OR}=0.992)$. As for motives, complex motives $(\mathrm{OR}=2.270)$ and other motives $(\mathrm{OR}=2.665)$ were extracted. Extracted as significant contemporaneous and postattempt influencing factors of GAS were: total BPRS score $(\mathrm{OR}=0.965)$; and psychotropic drug treatment $(\mathrm{OR}=2.463)$ or prescription $(\mathrm{OR}=0.417)$ and psychiatric therapy $(\mathrm{OR}=0.584)$ as treatment given.

\section{Discussion}

\section{Discussion based on results obtained from investigation items (Table 1)}

\section{Background factors}

Previous studies in Japan and overseas have typically reported that attempted suicide cases and completed suicide cases are more often female and male, respectively [14]. In particular, it has been assumed that a large proportion of suicide completers in Japan are middle-aged and older men, who are said to lack support-seeking action when faced with stress, keeping their troubles all to themselves and failing to receive therapeutic intervention until their condition becomes serious [15]. Consistent with this, the present study showed a high proportion of middle-aged and older men who belonged to the low score group. It has previously been pointed out that there is a considerably strong association between unemployment rate and suicide rate [16,17], with the suicide rate in the unemployed being reported to be approximately seven times higher than in the employed, regardless of gender, and higher in men than women [14]. This is consistent with the present 
study, in which a high proportion of the unemployed belonged to the low score group.

\section{ICD-10 diagnosis, history of psychiatric consultation, advice seeking, history of suicide attempts, life events and motives}

It has been reported, from results of psychological autopsies in Western countries, that approximately $90 \%$ of suicide victims have mental disorder [18-20], 50\% of which is reported to be accounted for by depression [21,22]. In the present study, $42.7 \%$ of all suicide attempters had mood disorder, with the low score group showing a particularly high percentage of patients with this disorder. While suicidal ideation is experienced by many people in a temporarily depressed state under stress, in many cases it resolves spontaneously with time. However, suicidal ideation may progress to suicide attempt in patients with mood disorder, due to: decreased social function associated with temporary leave from work, divorce, solitude, etc.; psychological tunnel vision; and decreased self-esteem. [23] In addition, while the present study found only a small number of patients whose primary diagnosis is substance-related disorders (F1) related to suicide-related behavior, there were also occasional patients who had comorbid substance-related disorders behind their disorders falling under the F3 or F4 category. Since substance-related disorders are closely related to decreased social function, as seen in the fact that many suicide attempters are in a drunken condition when going into suicide-attempting action, we believe that patients with suicidal behavior and substance-related disorders require further investigation.

The proportion of current regular psychiatric outpatients was lower in the high score group. There is a report that patients who can be diagnosed with adjustment disorder or personality disorder were less likely to continue regular psychiatric visits at one year after suicide attempt and were more likely to make further suicide attempts, as compared to other patients [24]. This was also true in the present study, in which patients in the high score group tended to seek medical attention only in an emergency and not to continue regular visits. It is considered that patients belonging to this group, which has a high proportion of patients diagnosed with neurosis, have problems in creating motivation to continue psychiatric visits and maintaining stability of symptoms.

While history of suicide attempts has previously been pointed out as an important risk factor for suicide [25-27], it has also been reported that middle-aged and older men with mood disorder are more likely to complete suicide at first attempt and to belong to the $\mathrm{AD}$ group [7,24,28-29]. The latter characteristics are similar to those of the low GAS score group in the present study, suggesting that the primary prevention of suicide is more important in this group.Life event stress values were higher in the low score group. While life events are significant as a starting point for the suicide process [30], it is difficult to prevent life events themselves. What is important is to screen for those who are exposed to highly stressful life events and to help them reduce stress from those events. In terms of motives, interpersonal relationship was less often the motive in the low score group while it was more often the motive in the high score group. This seems to reflect the situation where, in the low score group which has a higher proportion of middle-aged and older men, suicide attempts were triggered by a feeling of self-condemnation specific to mood disorder rather than by a clinical condition arising in reaction to stressful interpersonal relationships, whereas in the high score group which has a higher proportion of relatively young women, the occurrence of suicide attempts depended more on interpersonal relationship events. It has also been pointed out that suicide cases in young people are more likely to occur under the influence of interpersonal relationship events, and that women face a higher risk of this type of suicide [31,32].

\section{Psychiatric symptoms}

The total BRPS score was significantly higher in the middle score group. This means that when an overall functional assessment by the GAS is combined with a psychiatric clinical picture represented by the BPRS, patients' conditions were found to be most serious in the group of patients whose score was between 21 and 40, among those suicide attempt cases brought to an emergency department. The reason for this is not easy to explain. However, in light of the fact that patients in the high score group had relatively mild symptoms and clinical picture, and that those in the low score group were severely ill mainly with mood disorder, complaints of symptoms by patients in these two groups might have been masked and failed to be reflected in the assessments.

\section{Methods of suicide attempt, physical severity, outcome and treatment}

Beautrais and her colleagues have concluded that there are various similarities between emergently admitted suicide attempters who used a highly lethal method and suicide completers, and that these two groups can be understood as closely resembling to each other [33]. This is consistent with the present study, in which patients in the low score group were more likely to choose a highly lethal method, such as hanging, jumping from height or use of gas, and were also more likely to complete suicide, suggesting that low GAS scores indicate extremely serious risk. As for treatment given on the day, more than $80 \%$ of all suicide attempters in the present study were given physical treatment, which was combined with psychiatric therapy in approximately $20 \%$ of the cases. In particular, a high proportion of patients in the high score group were discharged to home after symptomatic treatment, mainly psychotropic and/or other drug treatment at the emergency department. In this group, psychiatric symptoms tended to be diagnosed as not serious and tended not to attract emergent psychiatric treatment, such as psychiatric therapy at the emergency department or psychiatric hospitalization. The middle score group was mainly given physical treatment and psychotropic drug subscription, partly due to the serious nature of the methods used. In the low score group, a higher proportion of patients were hospitalized, suggesting that they were in a psychiatric crisis.

\section{Summary of characteristics of each GAS score group and measures to be taken according to these characteristics} (Tables 2 and 3)

A suicide crisis commonly stems from the individual's personal, mental and social vulnerabilities, and emerges in a pattern formed by a combination of these vulnerabilities [34]. It is therefore necessary to provide preventive measures for the patient and his/her family members starting from an early stage, by understanding the characteristics of the patient, identifying associated factors that may act as a trigger, and studying patterns in which a suicide crisis may emerge. For the low score group, a representative profile can be described as an unemployed, middle-aged or older man who has been diagnosed with mood disorder and regularly sees a psychiatrist, and who was seen at the Hospital for the first time after his first suicide attempt, which was caused by stressful life events and for which he 
chose a dangerous method such as hanging, jumping from height or use of gas, resulting in hospitalization or completed suicide. This group can be regarded as so-called high-risk suicidal patients, partly due to its high odds ratio of 5.257 for the incidence of completed suicide. It is likely that patients in this group had compromised global function for a certain period of time before their suicide attempt and, despite the necessity for preventive intervention, failed to receive appropriate intervention, which led to suicidal action. The fact that being male, advanced age and unemployed were extracted as associated factors in this group suggests that, in addition to being a middle-aged or older man as a background factor, a failure to fulfill one's social roles may develop into suicide attempts. Furthermore, having high life event stress values was also identified as an associated factor. Considering that this group has a higher proportion of critically-ill patients after the first suicide attempt than the other groups, this group would require: an approach that makes use of paramedics who can provide prompt, practical cooperation to medical institutions; and training programs for gatekeepers who can be around these patients to help them. In the case of patients who are already regular psychiatric outpatients, it is necessary to prevent transition to suicide attempts by appropriately diagnosing their mood disorder and checking for any suicidal ideation. In doing so, it would also be important to: make efforts to improve their social roles by providing programs to help them return to work or find a new job; and keep watchful eyes on their life events.

As for the middle score group, a typical patient in this group would be able to take support-seeking action, such as seeking medical attention and continuing regular visits, but would be prone to have anxiety or other psychiatric symptoms due to life events at hand or isolation from the surroundings, indicating his/her vulnerability to stress and potential risk of suicide. While this group had a reduced risk of suicide associated with history of suicide attempts within the previous year, past history of suicide attempts was still a risk factor for suicide attempts in this group. Joiner and his colleagues have pointed out the "acquired capability for suicide" as an important risk factor for suicide [35]. The acquired capability for suicide means insensitivity to physical pain and a lack of a sense of fear, both acquired from repeated experiences of suicide-related behavior, etc. Joiner assumes that these experiences serve as rehearsals of a sort for suicide and lower the threshold for suicidal action. In this group, small life events may develop into suicide attempt behavior in the subset of patients who have history of suicide attempts, a potential risk factor for suicide, because of their impulsiveness and characteristic of seeking to solve problems by suicide-related behavior. This is so even if these patients are under psychiatric intervention and have exhibited no suicide attempt behavior in recent years. With respect to those patients in this group who regularly see a psychiatrist, we believe it important to continuously take a psychotherapeutic approach to enhance specific stress coping skills that would help them solve problems.

As for the high score group, a typical patient representing the characteristics of this group would be a relatively young woman who has no regular psychiatrist and chooses a non-lethal method of suicide due to mild psychiatric symptoms stemming from complex causes such as interpersonal relationship. Because of their mild physical symptoms, a high proportion of the patients in this group were diagnosed with transient stress reaction and were discharged to home after symptomatic treatment only. The fact that complex motives were extracted as a risk factor for the occurrence of this group implies their vulnerability to various stressors and anxiety-provoking situations experienced in daily life, a characteristic of neurosis. Patients in this group also tended to make suicide attempts even though they had sought advice from those around them. Considering the low proportion of patients in this group who continue regular psychiatric visits, we believe it important to provide this group with more readily accessible support and care, such as community programs for suicide prevention and awareness intended to provide patients and those around them with education on patients' stress coping and what those around them should do if they are asked for advice by a patient on his/her suicidal ideation. For patients who regularly see a psychiatrist, it is necessary to ensure that their symptoms remain stable, by providing them with education on their disease and guidance on the necessity for continuous regular visits.

In the present study, no association was found between any GAS score level and treatment outcome. It is considered that posttreatment outcome is determined not only by GAS scores but also by methods of suicide attempt, physical severity and treatment chosen.

\section{Usefulness of GAS scores in the assessment of suicide risk}

In the assessment of suicide risk, it is important to get a comprehensive picture of the patient using the GAS and to determine the characteristics of, and measures to be taken for, the suicide attempter by assessing the picture. Assessment of suicide risk is a key issue in suicide prevention. The GAS allows comprehensive assessment of mental status, not only in psychosis but also in neurosis or transient psychogenic reaction. The results of the present study provide additional evidence that suicide occurs in patients with various symptoms and in various disease categories. The GAS can also be used by paramedics by providing them with a preparatory learning course and a training and assessment course, and has been reported to produce fairly stable inter-rater reliability, subject to a certain level of training [5]. The results of the present study suggest that patients at different GAS score levels need different types of staff and that, in particular, patients with lower GAS scores need a wider range of specialist staff to improve global function, from healthcare professionals and health nurses to social support, etc. Unlike other assessment scales, the GAS has a small number of items and allows assessment based on a single item, making time for interview (such as structured interview) unnecessary and enabling itself to be used continuously in busy clinical settings.

The GAS allows assessment of long-term changes in a patient's functional level, due to the scale's ability to assess a wide range of states, from mentally healthy state to state of imminent suicidal crisis, as well as due to its availability in both inpatient and outpatient settings. As part of a suicide prevention strategy, the GAS allows assessment of treatment and living conditions of high-risk patients and provides an important guide to give support suited to such conditions. We believe that future use of the GAS throughout the process from emergency settings to admission and discharge and further to community care will contribute to the provision of seamless care, from emergency to community care, as well as to the final goals of achieving self-reliance and social reintegration of patients.

\section{Conclusion}

In the present study, we determined the characteristics of suicide attempters according to their GAS-based severity levels, and presented factors associated with the occurrence of suicide attempts. Our results suggest that taking measures for suicide attempters according to the 
characteristics of their GAS-based severity levels may lead to the prevention of further suicide attempts.

\section{Limitations}

\section{Author's contributions}

MU EJ and YT assessed the patients, analyzed the data and wrote the paper. AS and $\mathrm{KO}$ supervised and wrote the paper. HN participated in the design of the study and performed the statistical analysis. EJ,et al participated in the study as a whole and commented on the manuscript. SE conceived the study,and participated in its design and coordination. All authors approved the final manuscript.

\section{Acknowledgements}

This study was confined to a single medical institution in one community in Japan. In addition, GAS scores were not available for many suicide completers due to lack of information; only findings at emergency consultation were available in these cases. And, this study is not a comparative study of suicide completers as a whole; the study population excludes suicide completers who were not transported to any emergency care center.

\section{References}

1. American Psychiatric Association (2004) American Psychiatric Association Practice Guidelines for the Treatment of Psychiatric Disorders.

2. Otsuka K, Sakai A, Yambe T, Endo J, Iwato S, et al. (2011) Suicide attempter Care. Japanese journal psychiatric treatment 26: 1247-1254.

3. Endicott J, Spitzer RL, Fleiss JL, Cohen J (1976) The global assessment scale. A procedure for measuring overall severity of psychiatric disturbance. Arch Gen Psychiatry 33: 766-771.

4. Hayashi N (2010) Assessment of global functioning GAS and GAF. Jpn J Clin Psychiatry 39: 49-53.

5. Hayama U, Kawano M (1992) Interrater rellabirity and concurrent validity tests of the global assessment scale. Journal of Japan Academy of Psychiatric and Mental Health Nursing 1: 35-44.

6. Endo J, Otsuka K, Yoshida T, Nakamura H, Yambe T, et al. (2009) On factors related to risk to life in attempted suicides: comparison between absolutely and relatively dangerous suicides in emergency \& critical care center. The Journal of the Japanese Association for Emergency Psychiatry 12: 60-73.

7. Yambe T, Otsuka K, Sakai A (2008) Comparison of suicidal persons by gender and age group. The journal of the iwate medical association 151-162.

8. Kishi Y, Hosaka T, Kurosawa H (2000) Suggestion about the suicide statistical table in the critical care center. Jornal of Clinical and Experimental Medicine 194: 555-559.

9. Hashimoto E, Sakaguchi S, Shiga M, Ikeda N, Toki S, et al. (2001) Epidemiological studies of tobacco smoking and dependence in Japan. Alcohol 24: 107-110.

10. Holmes TH (1978) Life situations, emotions, and disease. Psychosomatics 19: 747-754.

11. Kitamura T, Machizawa S, Maruyama S, Nakagawa $Y$, Morita M, et al. (1985) Reliability of re-test of Brief Psychiatric Rating Scale (BPRS).Journal of mental health 32: 1-15.
12. Asukai N (1995) Suicide and mental disorders. Psychiatry Clin Neurosci 49 Suppl 1: S91-97.

13. Rahe RH, Mahan JL Jr, Arthur RJ (1970) Prediction of near-future health change from subjects' preceding life changes. J Psychosom Res 14: 401-406.

14. [No authors listed] (2010) [Access to, and exit from, medical treatment for depression: issues related to diagnosis and rehabilitation]. Seishin Shinkeigaku Zasshi 112: 1037-1047.

15. Matsumoto T Adulthood.Actual of suicide prevention :Nagai Press;2009.

16. Lewis G, Sloggett A (1998) Suicide, deprivation, and unemployment: record linkage study. BMJ 317: 1283-1286.

17. Mann JJ (2002) A current perspective of suicide and attempted suicide. Ann Intern Med 136: 302-311.

18. Bertolote JM, Takahashi Y, Yamamoto T (2007) Suicide prevention: a feasible global and local need. Clinical psychiatry 49: 547-552.

19. Robins e, Murphy GE, Wilkinson RH jr, gassner S, kayes J (1959) Some clinical considerations in the prevention of suicide based on a study of 134 successful suicides. Am J Public Health Nations Health 49: 888-899.

20. Kishi Y, Kurosawa H (2000) Summary of the actual situation of suicide attempters transported to the critical care center. Jornal of Clinical and Experimental Medicine 194: 589-590.

21. Cavanagh JT, Carson AJ, Sharpe M, Lawrie SM (2003) Psychological autopsy studies of suicide: a systematic review. Psychol Med 33: 395-405.

22. Health and Labor Sciences Research (2009) Study on diagnostication of the suicide that we applied a psychological autopsy database.

23. Takahashi $Y$ (2007) Suicide risk. Kongo Press.

24. Health and Labor Sciences Research (2004) The problems that watched from receipt behavior after the discharge of multiple suicide attempter admitted to the emergency center-one consideration the present conditions for psychiatric emergency service.

25. Crandall C, Fullerton-Gleason L, Aguero R, LaValley J (2006) Subsequent suicide mortality among emergency department patients seen for suicidal behavior. Acad Emerg Med 13: 435-442.

26. Ostamo A, Lönnqvist J (2001) Excess mortality of suicide attempters. Soc Psychiatry Psychiatr Epidemiol 36: 29-35.

27. Owens D, Horrocks J, House A (2002) Fatal and non-fatal repetition of self-harm. Systematic review. Br J Psychiatry 181: 193-199.

28. Isono $\mathrm{H}$, Otsuka $\mathrm{K}$, Hoshi $\mathrm{K}$, Yambe $\mathrm{T}$, Endo J, et al. (2008):A comparative study between Patients with mood disorder and with neurotic disorder who exhibited suicide-related behaviors. The journal of the iwate medical association 151-162.

29. Eto N, Kitamura T, Tanaka K, Ishikura H, Nishimura R (2012) Characteristics of Suicide Patients Admitted to the Emergency Unit;Retrospective Study on the First Attempt. Med.Bull.Fukuoka Univ 39: 179-189.

30. Kim YJ, Oh Y, Park S, Cho S, Park H (2013) Stratified sampling design based on data mining. Healthc Inform Res 19: 186-195.

31. Hawton K, van Heeringen K (2009) Suicide. Lancet 373: 1372-1381.

32. Bridge JA, Goldstein TR, Brent DA (2006) Adolescent suicide and suicidal behavior. J Child Psychol Psychiatry 47: 372-394.

33. Beautrais AL (2001) Suicides and serious suicide attempts: two populations or one? Psychol Med 31: 837-845.

34. Takahashi Y (2009) Long-term treatment for the patients who are at great risk of the suicide: Actual of suicide prevention.Nagai Press.

35. Joiner TE Jr, Van Orden KA, Witte TK,et al. (2009) The Interpersonal Theory of Suicide: Guidance for Working With Suicidal Clients. Washington D.C., American Psychological Association. 